\title{
Molecular biology of gynecological cancer (Review)
}

\author{
KENZO SONODA \\ Department of Obstetrics and Gynecology, Graduate School of Medical Sciences, \\ Kyushu University, Fukuoka, Fukuoka 812-8582, Japan
}

Received January 12, 2015; Accepted September 24, 2015

DOI: $10.3892 / \mathrm{ol} .2015 .3862$

\begin{abstract}
Cancer is a pathological condition in which the balance between cell growth and death is disordered. Various molecules have been reported to be involved in the oncogenic process of invasion, metastasis and resistance to treatment. An exponential growth in the collection of genomic and proteomic data in the past 20 years has provided major advances in understanding the molecular mechanisms of human cancer, which has been applied to diagnostic and treatment strategies. Targeted therapies have been developed and adopted, particularly for advanced, refractory or recurrent cancers, depending on individual molecular profiles. The aim of the present review is to provide a report of the current literature regarding the molecular biology of gynecological cancers.
\end{abstract}

\section{Contents}

1. Introduction

2. Oncogenesis

3. Escape from cell death

4. Angiogenesis, invasion and metastasis

5. Gynecological malignancies

6. Conclusion

Correspondence to: Dr Kenzo Sonoda, Department of Obstetrics and Gynecology, Graduate School of Medical Sciences, Kyushu University, 3-1-1 Maidashi, Fukuoka, Fukuoka 812-8582, Japan E-mail: kenzo@med.kyushu-u.ac.jp

Abbreviations: EGF, epidermal growth factor; GPCR, G-protein coupled receptor; RB1, retinoblastoma gene; cdk, cyclin-dependent kinase; TGF- $\beta$, transforming growth factor- $\beta$; HNPCC, hereditary nonpolyposis colorectal cancer syndrome; RCAS1, receptor-binding cancer antigen expressed on SiSo cells; VEGF, vascular endothelial growth factor; MMP, matrix metalloproteinase; PFS, progression-free survival; HPV, human papilloma virus; ORF, open reading frame; FHIT, fragile histidine triad gene; MSI, microsatellite instability; PARP, poly (ADP-ribose) polymerase; HB-EGF, heparin-binding EGF

Key words: gynecological cancer, molecular biology, oncogenesis, angiogenesis, targeted therapy

\section{Introduction}

Cancer is a complex collection of diseases that arise due to genetic and epigenetic alterations that interfere with cellular growth and death (1). Specific molecular alterations that induce a normal cell to become malignant, defined as the ability to invade and metastaize from the primary lesion, have been revealed, but the spectrum of these alterations vary substantially among cancers. It is now recognized that metastasis is dependent on a balance of stimulating signals and inhibitory factors, which must be weighted in favor of the stimulating signals to result in metastasis (2). Stem cell studies have provided valuable information for cancer biology. As studies continue to understand the role of cancer stem cells, the resulting information is likely to lead to novel approaches to target cancer cells (3). Although conventional combinations of surgery, radiation and chemotherapy remain the mainstay of cancer treatment, it is challenging to treat advanced or recurrent cancers in this way. An exponential growth in the collection of genomic and proteomic data in the past 20 years has resulted in the development of various targeted therapies (4). In addition, recent advances in biochemical engineering should contribute to a major evolution in the diagnosis and treatment of human cancer (5). The initial sections of the present review examine the literature regarding the basic molecular mechanisms involved in the development of cancers and the expansion of the malignant phenotype. The molecular changes characteristic of gynecological cancers are outlined in section 5 .

\section{Oncogenesis}

At least 3-6 changes are considered to be required to transform a cell (6). The majority of cancer cells are genetically unstable, and this leads to an accumulation of numerous secondary molecular alterations that play a role in the evolution of malignant characteristics, including immortality, invasion, metastasis and resistance to therapy (7). Epigenetics are hereditary changes that do not originate from DNA mutation (8). The primary mechanism of epigenetic alteration, which is regulated by a family of DNA methyltransferases, is methylation of cytosine residues that reside next to guanine (9). The majority of cancer types comprehensively reduce DNA methylation, a reduction that may contribute to genomic instability (10). Selective hypermethylation of cytosines in the promoter regions of tumor suppressor genes may lead to the 
inactivation of the genes, and this may result in carcinogenesis (11). Acetylation and methylation of the histone proteins that package and order the DNA into structural units, acts as another level of epigenetic regulation (11). These genetic and epigenetic alterations may become therapeutic targets against cancer.

Alterations in genes that stimulate cellular growth (oncogenes) are able to cause the malignant transformation of cells (12). Oncogenes are activated by several mechanisms, as follows: First, through the amplification of the oncogenes, which results in overexpression of the corresponding proteins; second, point mutations may overactivate oncogenes; and third, oncogenes may be translocated from one chromosome to another, affecting the promoter regions and resulting in overexpression of the gene (13). The third mechanism continually occurs in lymphomas and leukemias (14). Peptide growth factors, such as epidermal growth factor (EGF), platelet-derived growth factor, and fibroblast growth factor families, stimulate intracellular molecular pathways that lead to proliferation (15-17). Growth factor receptors that exist on the cell membrane are composed of an extracellular domain, a transmembrane region, and a cytoplasmic tyrosine kinase domain (18). Following binding of a growth factor, the receptor undergoes a conformational change, resulting in the activation of the tyrosine kinase in the cytoplasmic domain. The tyrosine kinase phosphorylates tyrosine residues on the receptor itself and on downstream molecular targets in the cytoplasm (19).

G-protein coupled receptors (GPCRs) are cell membrane receptors that contain a 7-transmembrane $\alpha$-helical fold, which transduces extracellular information into intracellular signal transduction pathways (20). GPCR signaling pathways are extremely complex and include the Ras superfamily guanosine triphosphatase (GTPase), one of the most frequently mutated oncogenes in humans (21). Harvey rat sarcoma viral oncogene homolog (H-RAS), Kirsten rat sarcoma viral oncogene homolog (K-RAS) and neuroblastoma rat sarcoma viral oncogene homolog are isoforms of the Ras protein and promote carcinogenesis when they are activated by mutations at codon 12 , 13 or 61 (22). Although a high degree of similarity exists among the isoforms, K-RAS mutations are most frequently identified in cancer and each isoform demonstrates preferential association to particular cancer types (23). B-Raf proto-oncogene, serine/threonine kinase (BRAF) is a serine/threonine-specific protein kinase that interacts with Ras proteins in activating the MAP kinase pathway (24). Notably, the most common BRAF mutation, the V600E transversion, has been identified in numerous types of human cancer (25). Signals generated in the cell membrane and cytoplasm, following GPCR binding, result in the activation of nuclear transcription factors that are responsible for stimulating cell growth, including the FOS and JUN oncogenes that form the activator protein 1 transcription complex by dimerization (26). The MYC gene family is also involved in the development of human malignancies (27), and when inappropriately amplified or overexpressed, these transcription factors may act as oncogenes.

Loss of tumor suppressor gene function plays a role in tumorigenesis (28). Statistical analysis of cancer incidence has proposed the two-hit theory for the inactivation of tumor suppressor genes; mutations in each of the alleles are necessary for the loss of tumor suppressor gene function (7). However, subsequent interpretations of the analysis indicated that mutations in tumor suppressor genes are not absolutely recessive (7). Haploinsufficiency is a condition where only a single functional copy of a gene is produced (29). In a tumor suppressor gene, haploinsufficiency leads to the development of cancer (30). The phenotypic penetrance of tumor suppressor gene mutations may be affected, not only by the nature of the mutation itself, but also by other clinicopathological variables, including genetic background, tissue type and environmental factors (31). Certain tumor suppressor genes are inactivated by methylation of the promoter region of the gene (32). Examples include the retinoblastoma gene (RB1) in retinoblastoma (33), the Von Hippel-Lindau gene in renal carcinomas (34), the BRCA gene in breast cancer (35) and the APC gene in colorectal cancer (36). RB1 was the first tumor suppressor gene to be identified (37), and plays a pivotal role in the regulation of cell cycle progression. In the $\mathrm{G} 1$ phase of the cell cycle, the Rb protein, which is upregulated when RB1 is transcribed, binds to the E2F transcription factor and prevents cell cycle progression (38). When $\mathrm{Rb}$ is phosphorylated by cyclin and cyclin-dependent kinase (cdk) complexes, E2F is released and the cell cycle progresses. The RB1 gene mutation has been identified in retinoblastoma and certain types of sarcoma, but rarely in other types of cancer, unlike the tumor protein p53 (TP53) tumor suppressor gene, which is mutated in the majority of human cancers $(39,40)$.

The p53 protein is a sensor of multiple forms of genetic toxicities and oncogenic stresses. Since the p53 protein represses growth and regulates the survival of stressed cells, it has been described as the 'guardian of the genome' (7). The clonal expansion of cells with the TP53 gene mutation may proceed to carcinogenesis (41). Numerous cancer cells possess missense mutations in exons 5-8 in one copy of the TP53 gene, which encode the DNA binding domains, and even though a deletion of the other copy of the TP53 gene does not occur, the mutant p53 protein is able to complex with the wild-type p53 protein and disturb the interaction between the wild-type p53 protein and DNA in a dominant negative fashion (42).

Although numerous tumor suppressor genes encode nuclear proteins, such as TP53 and RB1, certain intra-cytoplasmic tumor suppressor molecules have been identified, including: Phosphatase and tensin homolog (PTEN), which inhibits invasion and metastasis by modulating the cytoskeleton (43); a mutant version of the APC gene that is responsible for familial adenomatous polyposis syndrome (44); and transforming growth factor- $\beta$ (TGF- $\beta$ ) protein, which is coded by the TGFB1 gene and inhibits the proliferation of normal epithelial cells (45). Additionally, the altered expression of microRNAs, which are single RNA strands of 21-23 nucleotides, has been detected in numerous cancers (46).

Families with inherited mutations in genes susceptible to cancer exhibit a high incidence of specific types of cancer (47). In addition, the age of cancer onset is younger and certain individuals experience multiple primary cancers $(48,49)$. Mutations of tumor suppressor genes and DNA mismatch repair genes are usually involved in familial cancer syndromes, such as breast cancer 1 , early onset (BRCA1) and breast cancer 2 , early onset (BRCA2) in hereditary breast or ovarian cancer syndrome (50), APC in familial adenomatous polyposis syndrome (51), and MSH2, MLH1 and MSH6 in hereditary nonpolyposis colorectal cancer syndrome (HNPCC) (52). 


\section{Escape from cell death}

The number of cells in normal tissues is strictly controlled by a balance between cell growth and death. Cell proliferation is regulated by the cell cycle, in which numerous molecules, are involved, including TP53, Rb, E2F, cyclins and cdks (53). Cancer cells lose cell cycle regulatory systems and are resistant to death and senescence (54). The three major cell death pathways are apoptosis, necrosis and autophagy (55). Apoptosis is an energy-dependent process in which DNA and proteins are cleaved by endonucleases and proteases, respectively (56). Apoptotic stimuli are delivered through an extrinsic or intrinsic pathway and may contribute to the prevention of cancer by eliminating transformed cells (57). Necrosis of cells instigates a strong immune response, and various anticancer agents stimulate a beneficial immune response by enhancing the necrosis of tumor cells (58). Autophagy is characterized by the degradation of cellular proteins and organelles in fused cytoplasmic autophagic vesicles and lysosomes (59). Cellular senescence is regulated by progressive shortening of telomeres (60). Cancer cells are capable of avoiding senescence by enhancing a ribonucleoprotein complex telomerase, and in gynecological malignancies high activity levels of telomerase are identified (61).

With regard to immune surveillance, cancer cells have developed mechanisms to evade immune responses and prolong survival. The receptor-binding cancer antigen (RCAS1), which is expressed on SiSo cells, may induce apoptosis in immune cells, including peripheral lymphocytes and natural killer cells (62). The involvement of RCAS1 in tumor cell escape from immune surveillance has been investigated using clinical specimens, as reviewed by Giaginis et al (63). In cervical cancer, the number of tumor cells expressing RCAS1 was significantly associated with the number of apoptotic lymphocytes at the primary site and in metastatic lymph nodes (64). In glioma and oral squamous cell, lung, breast, esophageal, gastric, biliary tract and colon cancers, increased numbers of apoptotic lymphocytes or decreased numbers of tumor-infiltrating lymphocytes have been reported (65). These observations suggest that RCAS1 plays a pivotal role in tumor cell evasion of immune surveillance. The signal transduction pathways that induce apoptosis following RCAS1 stimulation have been assessed; RCAS1 induced p38 MAPK phosphorylation (66), cytochrome $c$ release and activation of caspase-3, but decreased cyclin D3 levels (67). However, RCAS1-induced apoptosis is strongly inhibited by the cysteine protease inhibitor benzyloxycarbonyl-Val-Ala-Asp fluoromethylketone (62).

\section{Angiogenesis, invasion and metastasis}

Angiogenesis is required for cancer cell proliferation. Various mediators of angiogenesis have been reported, including vascular endothelial growth factor (VEGF), interleukin-8 and matrix metalloproteinases (MMP) (68). Targeted therapy against angiogenesis using bevacizumab, a humanized VEGF-neutralizing monoclonal antibody, improved the median progression-free survival (PFS) rate in advanced ovarian cancer (69). Burger et al reported that the use of bevacizumab during and following carboplatin and paclitaxel chemotherapy prolonged the median progression-free survival time in patients with advanced epithelial ovarian cancer (69). In addition, debulking surgery following neoadjuvant chemotherapy, such as bevacizumab, did not increase the rate of post-operative complications (70).

A crucial first step of metastasis is invasion of cancer cells through the basement membrane of tissues. MMPs promote cancer cell invasion and endothelial cell migration (71) and were reported to be expressed at the invasive front of endometrial and ovarian cancer (72). Furthermore ovarian cancers that overexpress MMP-2 and MMP-9 demonstrate aggressive clinical characteristics $(73,74)$. Adhesion molecules including focal adhesion kinase, integrins and E-cadherin may facilitate cancer progression. Sawada et al reported that $\alpha 5$-integrin upregulation was a molecular mechanism that led to a loss in E-cadherin, thereby promoting ovarian cancer cell metastasis (75). The propensity of various types of cancer to metastasize in specific organs was first proposed by Paget in 1889 (76). Paget's hypothesis stated that metastasis resulted from the dependence of the seed (cancer cell) on the soil (metastatic site), and was devised due to the non-random pattern observed with metastasis. Recent studies provide important information for this non-random pattern of metastasis. Breast cancers frequently metastasize to the lung, liver and bone marrow (77). Tumor cells also express high levels of chemokine (C-X-C motif) receptor 4 and CC chemokine receptor 7 , and chemokine proteins chemokine (C-X-C motif) ligand 12 and chemokine (C-C motif) ligand 21 are detected at high levels in metastatic sites (78).

Several studies have suggested that RCAS1 may be involved in the aggressive characteristics of human malignancies, not only by helping tumor cells to evade immune surveillance, but also by inducing cancer stromal tissue remodeling (79). For example, in cervical cancer, RCAS1 expression levels were significantly correlated with those of MMP-1, an interstitial collagenase, and laminin-5, an extracellular matrix molecule (80), which have been reported to be involved in tumor invasion and metastasis (81-82). Additionally, the number of stromal vimentin-positive cells was revealed to decrease in association with the RCAS1 expression level in cervical and ovarian cancer $(79,84)$. The reduction in vimentin expression may result in tumor progression, since vimentin is involved in apoptosis (83) and the mechanical stability of stromal cells (85-87). Furthermore, RCAS1 expression is significantly associated with VEGF expression and microvessel density in cervical cancer (88). RCAS1 is hypothesized to induce VEGF expression through the TGF- $\beta$ and MAPK signaling pathways. Liby et al reported that a blockade of protein kinase B (Akt)-3 resulted in smaller and less vascularized tumors with a downregulation of RCAS1 and VEGF expression in a xenograft mouse model (89). MMPs and laminin also play an important role in angiogenesis via regulation of extracellular matrix degradation and remodeling (90).

\section{Gynecological malignancies}

Cervical cancer. Worldwide, cervical cancer was the fourth most commonly diagnosed malignancy in women in 2012, with an estimated 527,600 novel cases and 265,700 fatalities (91). Overall, $\sim 85 \%$ of novel cases and mortalities occurred in developing countries. Human papilloma virus (HPV) has been reported to play a pivotal role in the carcinogenesis of cervical cancer (92). HPV DNA is composed of 7,800 nucleotides that include early and late open reading frames (ORFs) (93). Early 
ORFs encode 7 proteins, termed E1-7, that are involved in viral replication and host cell transformation (94). Late ORFs encode structural proteins of the virion, such as L1 and 2. Cellular transformation may be associated with the integration of HPV DNA into the host genome, for example E6 and 7 bind to and inactivate p53 and $\mathrm{Rb}$, respectively, resulting in transformation. This observation suggests that the oncogenic potential of HPV is associated with the binding affinities of E6 and 7 (95,96).

The majority of HPV infections spontaneously regress, and only a small proportion of HPV-infected individuals develop cervical cancer (97). Additive molecular alterations to HPV infections are considered to be required for the progression to cervical cancer, but these changes are not yet fully understood. Comparative genomic hybridization analysis has revealed the addition of chromosomes $1 \mathrm{q}$ and $3 \mathrm{q}$ and the loss of chromosomes $2 \mathrm{q}, 3 \mathrm{p}$ and $11 \mathrm{q}$ in cervical cancer (97). The fragile histidine triad gene (FHIT) is located in chromosome $3 \mathrm{p}$ and FHIT expression is frequently reduced in cervical cancer (98). Since allelic losses and homozygous deletions, as well as loss of heterozygosity, are frequently detected in microsatellites in FHIT, alterations and inactivation of the FHIT gene are presumed to contribute to and accelerate cervical carcinogenesis, for example decreased expression of FHIT and overexpression of p16 and c-myc are considered to be early events in cervical cancer (99). Mutations in the K-RAS or H-RAS genes are suggested to be a late event for cervical carcinogenesis (100). RCAS1 expression has been immunohistochemically studied during the carcinogenesis of cervical cancer and was not detected in dysplasias; however, $20 \%$ of carcinomas in situ, $16 \%$ of microinvasive carcinomas, and $82 \%$ of invasive carcinomas stained for the expression of RCAS1 (101). Therefore, RCAS1 expression may be associated with tumor progression and invasion in the squamous cell epithelium of the cervix.

Endometrial cancer. Endometrial cancer is the most commonly diagnosed gynecological malignancy in developed countries (102). In the USA, a projected 54,870 patients are expected to be diagnosed and 10,170 cases are expected to be fatal in 2015 (103). Between 2006 and 2010, the incidence of novel cases of endometrial cancer increased by $1.5 \%$ per year among females aged $<50$ years and $2.6 \%$ per year among females aged $\geq 50$ years. In the same period, mortality from endometrial cancer increased by $1.5 \%$ per year among females aged $<50$ years, but were stable among females aged $\geq 50$ years. The majority of endometrial cancers are sporadic, $\sim 5 \%$ of cases are considered to be hereditary and caused by DNA mismatch repair gene mutations (104). Endometrial cancer is the second most commonly diagnosed malignancy in females with HNPCC (105).

Endometrial cancers are classified as Type I or II, according to clinicopathological variables (106). Type I endometrial cancer arises from preneoplastic lesion hyperplasia that has undergone unchecked estrogenic stimulation (107). During menopause, estrogens are produced from androgens secreted from adrenal glands and non-specialized ovarian stroma. Niwa et al reported that estrone was the most effective estrogen to promote endometrial carcinogenesis in a mouse model (108). Almost $80 \%$ of Type I endometrioid adenocarcinomas exhibited a loss of PTEN expression (109), and mutations of K-RAS and $\beta$-catenin are frequently detected (110). Microsatellite instability (MSI) is a significant genetic alteration demonstrated in almost $45 \%$ of endometrial cancer lesions (111) that results from impaired DNA mismatch repair. Cells without normally functioning DNA mismatch repair cannot correct errors, including single base mismatches, insertions and deletions during DNA replication. Mismatch repair gene MLH1 deficiency, caused by epigenetic hypermethylation in its promoter region, is most frequently observed in sporadic endometrial adenocarcinomas. Loss of PTEN expression, K-RAS mutation and MSI are suggested to be early events in endometrial carcinogenesis. Type II carcinomas develop from atrophic endometrium and are frequently serous or clear cell adenocarcinomas. TP53 mutations occur in 90\% of serous adenocarcinomas and are almost always associated with aneuploidy (112). p16 inactivation, HER2 overexpression, and reduced E-cadherin expression are observed in $\sim 45,70$, and $80 \%$ of cases, respectively $(113,114)$.

RCAS1 expression was investigated during the carcinogenesis of endometrial cancer, and was significantly increased in endometrial adenocarcinoma compared with normal cells or hyperplasias, suggesting that RCAS1 expression may be associated with oncogenic transformation (115). RCAS1 expression was revealed to be inversely correlated with the prognosis of patients with endometrial cancer (116).

Ovarian cancer. The majority of ovarian cancers are sporadic and arise from an accumulation of genetic damage (117). Ovarian cancers are heterogeneous regarding histopathology and malignant potential; therefore, the characteristic patterns of molecular signature are also varied (118). Serous borderline tumor and low-grade serous adenocarcinoma are frequently characterized by mutations in K-RAS and BRAF (119). Sporadic high-grade serous adenocarcinoma is usually advanced at diagnosis and the prognosis of patients is poor. Ovarian cancer has frequent mutations in TP53 and occasional overexpression of HER-2/neu, AKT2 and MYC (120,121). Endometrioid and clear cell adenocarcinomas have been suggested to associate with endometriosis and possess frequent mutations of PTEN and PIK3CA (122). Mucinous adenocarcinoma is usually diagnosed at an early stage of disease and characterized by mutations in K-RAS (123). In total, $\sim 10 \%$ of ovarian cancers are attributable to inherited mutations of cancer susceptibility genes, including BRCA1 and BRCA2 (124), and high-grade serous adenocarcinoma is a predominant histological type in patients with inherited BRCA mutations. BRCA1 and BRCA2 are located in chromosome $17 \mathrm{q}$ and $13 \mathrm{q}$, respectively (125). Since the BRCA1 and BRCA2 proteins complex with Rad51 recombinase and other molecules that are involved in the repair of DNA double strand breaks by homologous recombination, BRCA1 and BRCA 2 are classified as tumor suppressor genes (126). The life-time risk of ovarian cancer ranges between $20-40 \%$ and $10-20 \%$ in BRCA1 and BRCA 2 carriers, respectively, and the median age of patients is 40-50 years old (127-129). Poly(adenosine diphosphate-ribose) polymerase (PARP) is involved in the repair of DNA single strand breaks by base excision. The efficacy of a PARP inhibitor was investigated in ovarian cancer patients with BRCA mutations (130). Randomized phase II 
studies of platinum-sensitive recurrent high-grade serous cancers (both germline BRCA and sporadic) showed that patients treated with a PARP inhibitor exhibited a significant improvement in PFS when compared with patients who were administered a placebo (131).

Lysophosphatidic acid, heparin-binding EGF (HB-EGF) and amphiregulin, have been reported to play pivotal roles in proliferation and dissemination of ovarian cancer $(132,133)$. Yagi et al reported that inhibitory agents against HB-EGF, including CRM197, were possible chemotherapeutic and chemosensitizing agents for ovarian cancer (134). The clinical application of novel treatments which target these molecules is expected in the future.

\section{Conclusion}

Since it is challenging to treat advanced or recurrent cancers using conventional treatments, the development of novel and highly specific targets for therapy is required. An exponential growth in the collection of genomic and proteomic data in the past 20 years has provided major advances in understanding the molecular mechanisms of human cancer. This progress has resulted in the development of targeted therapies tailored to an individual molecular profile. Recent advances in biochemical engineering should contribute to major evolution in diagnosis and treatment of human cancer.

\section{Acknowledgements}

This review was supported in part by a Grant-in-Aid for Scientific Research from the Japan Society for the Promotion of Science (grant no. 24592519).

\section{References}

1. Hoeijmakers JH: DNA damage, aging, and cancer. N Engl J Med 361: 1475-1485, 2009.

2. Entschladen F, Drell TL IV, Lang K, Joseph J and Zaenker KS: Tumour-cell migration, invasion, and metastasis: Navigation by neurotransmitters. Lancet Oncol 5: 254-258, 2004.

3. Meacham CE and Morrison SJ: Tumour heterogeneity and cancer cell plasticity. Nature 501: 328-337, 2013.

4. Mok TS: Personalized medicine in lung cancer: What we need to know. Nat Rev Clin Oncol 8: 661-668, 2011.

5. Diou O, Tsapis N and Fattal E: Targeted nanotheranostics for personalized cancer therapy. Expert Opin Drug Deliv 9: 1475-1487, 2012.

6. Croce CM: Oncogenes and cancer. N Engl J Med 358: 502-511, 2008.

7. Hanahan D and Weinberg RA: Hallmarks of cancer: The next generation. Cell 144: 646-674, 2011

8. Esteller M: Epigenetics in cancer. N Engl J Med 358: 1148-1159, 2008.

9. Berdasco $\mathrm{M}$ and Esteller $\mathrm{M}$ : Aberrant epigenetic landscape in cancer: How cellular identity goes awry. Dev Cell 19: 698-711, 2010.

10. Esteller M: Cancer epigenomics: DNA methylomes and histone-modification maps. Nat Rev Genet 8: 286-298, 2007.

11. Jones PA and Baylin SB: The epigenomics of cancer. Cell 128: 683-692, 2007.

12. Doroshow JH and Kummar S: Translational research in oncology - 10 years of progress and future prospects. Nat Rev Clin Oncol 11: 649-662, 2014.

13. Negrini S, Gorgoulis VG and Halazonetis TD: Genomic instability - an evolving hallmark of cancer. Nat Rev Mol Cell Biol 11: 220-228, 2010

14. Tomita N: BCL2 and MYC dual-hit lymphoma/leukemia. J Clin Exp Hematop 51: 7-12, 2011.
15. Maire CL and Ligon KL: Molecular pathologic diagnosis of epidermal growth factor receptor. Neuro Oncol 16: viii1-6, 2014.

16. Demoulin JB and Essaghir A: PDGF receptor signaling networks in normal and cancer cells. Cytokine Growth Factor Rev 25: 273-283, 2014.

17. Fearon AE, Gould CR and Grose RP: FGFR signaling in women's cancers. Int J Biochem Cell Biol 45: 2832-2842, 2013.

18. Normanno N, De Luca A,Bianco C, Strizzi L, Mancino M, Maiello MR, Carotenuto A, De Feo G, Caponigro F and Salomon DS: Epidermal growth factor receptor (EGFR) signaling in cancer. Gene 366: 2-16, 2006

19. Bishayee A, Beguinot L and Bishayee S: Phosphorylation of tyrosine 992, 1068, and 1086 is required for conformational change of the human epidermal growth factor receptor c-terminal tail. Mol Biol Cell 10: 525-536, 1999.

20. Heng BC, Aubel D and Fussenegger M: An overview of the diverse roles of G-protein coupled receptors (GPCRs) in the pathophysiology of various human diseases. Biotechnol Adv 31: 1676-1694, 2013.

21. Shaw RJ and Cantley LC: Ras, PI(3)K and mTOR signaling controls tumour cell growth. Nature 441: 424-430, 2006.

22. Prior IA, Lewis PD and Mattos C: A comprehensive survey of Ras mutations in cancer. Cancer Res 72: 2457-2467, 2012.

23. Fernández-Medarde A and Santos E: Ras in cancer and developmental diseases. Genes Cancer 2: 344-358, 2011.

24. Ho CL, Kurman RJ, Dehari R, Wang TL and Shih IeM: Mutations of BRAF and KRAS precede the development of ovarian serous borderline tumors. Cancer Res 64: 6915-6918, 2004.

25. Cantwell-Dorris ER, O'Leary JJ and Sheils OM: BRAFV600E: Implications for carcinogenesis and molecular therapy. Mol Cancer Ther 10: 385-394, 2011.

26. Eferl R and Wagner EF: AP-1: A double-edged sword in tumorigenesis. Nat Rev Cancer 3: 859-868, 2003.

27. Li Y, Casey SC and Felsher DW: Inactivation of MYC reverses tumorigenesis. J Intern Med 276: 52-60, 2014.

28. Payne SR and Kemp CJ: Tumor suppressor genetics Carcinogenesis 26: 2031-2045, 2005.

29. Berger AH and Pandolfi PP: Haplo-insufficiency: A driving force in cancer. J Pathol 223: 137-146, 2011.

30. Smith U: PTEN - linking metabolism, cell growth, and cancer. $\mathrm{N}$ Engl J Med 367: 1061-1063, 2012.

31. Chaudru V, Chompret A, Bressac-de Paillerets B, Spatz A, Avril MF and Demenais F: Influence of genes, nevi, and sun sensitivity on melanoma risk in a family sample unselected by family history and in melanoma-prone families. J Natl Cancer Inst 96: 785-795, 2004.

32. Sugimura T and Ushijima T: Genetic and epigenetic alterations in carcinogenesis. Mutat Res 462: 235-246, 2000.

33. Greger V, Debus N, Lohmann D, Höpping W, Passarge E and Horsthemke B: Frequency and parental origin of hypermethylated RB1 alleles in retinoblastoma. Hum Genet 94: 491-496, 1994.

34. Herman JG, Latif F, Weng Y, Lerman MI, Zbar B, Liu S, Samid D, Duan DS, Gnarra JR, Linehan WM, et al: Silencing of the VHL tumor-suppressor gene by DNA methylation in renal carcinoma. Proc Natl Acad Sci USA 91: 9700-9704, 1994.

35. Dobrovic A and Simpfendorfer D: Methylation of the BRCA1 gene in sporadic breast cancer. Cancer Res 57: 3347-3350, 1997.

36. Arnold CN, Goel A, Niedzwiecki D, Dowell JM, Wasserman L, Compton C, Mayer RJ, Bertagnolli MM and Boland CR: APC promoter hypermethylation contributes to the loss of APC expression in colorectal cancers with allelic loss on 5q. Cancer Biol Ther 3: 960-964, 2004.

37. Madhavan J, Ganesh A and Kumaramanickavel G: Retinoblastoma: From disease to discovery. Ophthalmic Res 40: 221-226, 2008.

38. Guimaraes DP and Hainaut P: TP53: A key gene in human cancer. Biochimie 84: 83-93, 2002.

39. Lipinski MM and Jacks T: The retinoblastoma gene family in differentiation and development. Oncogene 18: 7873-7882, 1999.

40. Soussi T: The history of $\mathrm{p} 53$. A perfect example of the drawbacks of scientific paradigms. EMBO Rep 11: 822-826, 2010.

41. Ghebranious N and Donehower LA: Mouse models in tumor suppression. Oncogene 17: 3385-3400, 1998.

42. Walerych D, Napoli M, Collavin L and Del Sal G: The rebel angel: Mutant p53 as the driving oncogene in breast cancer. Carcinogenesis 33: 2007-2017, 2012.

43. Chalhoub N and Baker SJ: PTEN and the PI3-kinase pathway in cancer. Annu Rev Pathol 4: 127-150, 2009. 
44. Jaiswal AS and Narayan S: A novel function of adenomatous polyposis coli (APC) in regulating DNA repair. Cancer Lett 271: 272-280, 2008

45. Tian M and Schiemann WP: The TGF-beta paradox in human cancer: An update. Future Oncol 5: 259-271, 2009.

46. Kong YW, Ferland-McCollough D, Jackson TJ and Bushell M: microRNAs in cancer management. Lancet Oncol 13: e249-258, 2012.

47. Lu KH: Hereditary gynecologic cancers: Differential diagnosis, surveillance, management and surgical prophylaxis. Fam Cancer 7 : 53-58, 2008.

48. Perea J, Rodríguez Y, Rueda D, Marín JC, Díaz-Tasende J, Álvaro E, Alegre C, Osorio I, Colina F, Lomas M, et al: Early-onset colorectal cancer is an easy and effective tool to identify retrospectively Lynch syndrome. Ann Surg Oncol 18: 3285-3291, 2011.

49. Nieuwenhuis MH, Kets CM, Murphy-Ryan M, Yntema HG, Evans DG, Colas C, Møller P, Hes FJ, Hodgson SV, Olderode-Berends MJ, et al: Cancer risk and genotype-phenotype correlations in PTEN hamartoma tumor syndrome. Fam Cancer 13: 57-63, 2014.

50. Kobayashi H, Ohno S, Sasaki Y and Matsuura M: Hereditary breast and ovarian cancer susceptibility genes (review). Oncol Rep 30: 1019-1029, 2013.

51. Rozen P and Macrae F: Familial adenomatous polyposis: The practical applications of clinical and molecular screening. Fam Cancer 5: 227-235, 2006

52. Vasen HF, Möslein G, Alonso A, et al: Guidelines for the clinical management of Lynch syndrome (hereditary non-polyposis cancer). J Med Genet 44: 353-362, 2007.

53. Harris SL and Levine AJ: The p53 pathway: Positive and negative feedback loops. Oncogene 24: 2899-2908, 2005.

54. Collado M and Serrano M: Senescence in tumours: Evidence from mice and humans. Nat Rev Cancer 10: 51-57, 2010.

55. Su Z, Yang Z, Xu Y, Chen Y and Yu Q: Apoptosis, autophagy, necroptosis, and cancer metastasis. Mol Cancer 14: 48, 2015

56. Hensley P, Mishra M and Kyprianou N: Targeting caspases in cancer therapeutics. Biol Chem 394: 831-843, 2013.

57. Lowe SW, Cepero E and Evan G: Intrinsic tumour suppression. Nature 432: 307-315, 2004

58. Vanden Berghe T, Linkermann A, Jouan-Lanhouet S, Walczak H and Vandenabeele P: Regulated necrosis: The expanding network of non-apoptotic cell death pathways. Nat Rev Mol Cell Biol 15: $135-147,2014$

59. Chaabane W, User SD, El-Gazzah M, Jaksik R, Sajjadi E, Rzeszowska-Wolny J and Los MJ: Autophagy, apoptosis, mitoptosis and necrosis: Interdependence between those pathways and effects on cancer. Arch Immunol Ther Exp (Warsz) 61: 43-58, 2013

60. van Deursen JM: The role of senescent cells in ageing Nature 509: 439-446, 2014

61. Sakamoto M, Toyoizumi T, Kikuchi Y, Okamoto A, Nakayama H, Aoki D, Yamamoto K, Hata H, Sugishita T and Tenjin Y: Telomerase activity in gynecological tumors. Oncol Rep 7: 1003-1009, 2000.

62. Nakashima M, Sonoda K and Watanabe T: Inhibition of cell growth and induction of apoptotic cell death by the human tumor-associated antigen RCAS1. Nat Med 5: 938-942, 1999.

63. Giaginis C, Giagini A and Theocharis S: Receptor-binding cancer antigen expressed on SiSo cells (RCAS1): A novel biomarker in the diagnosis and prognosis of human neoplasia. Histol Histopathol 24: 761-776, 2009.

64. Sonoda K, Miyamoto S, Hirakawa T, Yagi H, Yotsumoto F, Nakashima M, Watanabe T and Nakano H: Association between RCAS1 expression and microenvironmental immune cell death in uterine cervical cancer. Gynecol Oncol 97: 772-779, 2005

65. Sonoda K: RCAS1 is a promising therapeutic target against cancer: Its multifunctional bioactivities and clinical significance. Expert Rev Obstet Gynecol 7: 261-267, 2012

66. Sonoda K, Miyamoto S, Nakashima M and Wake N: The biological role of unique molecule RCAS1: A bioactive marker that induces connective tissue remodeling and lymphocyte apoptosis. Front Biosci 13: 1106-1116, 2008.

67. Nishinakagawa T, Fujii S, Nozaki T, Maeda T, Machida K, Enjoji $\mathrm{M}$ and Nakashima M: Analysis of cell cycle arrest and apoptosis induced by RCAS1. Int J Mol Med 25: 717-722, 2010.

68. Baeriswyl V and Christofori G: The angiogenic switch in carcinogenesis. Semin Cancer Biol 19: 329-337, 2009.

69. Burger RA, Brady MF, Bookman MA, et al; Gynecologic Oncology Group: Incorporation of bevacizumab in the primary treatment of ovarian cancer. N Engl J Med 365: 2473-2483, 2011
70. Chéreau E, Lambaudie E and Houvenaeghel G: Morbidity of surgery after neoadjuvant chemotherapy including bevacizumab for advanced ovarian cancer. Int J Gynecol Cancer 23: 1326-1330, 2013.

71. Hua H, Li M, Luo T, Yin Y and Jiang Y: Matrix metalloproteinases in tumorigenesis: An evolving paradigm. Cell Mol Life Sci 68: 3853-3868, 2011.

72. Planagumà J, Liljeström M, Alameda F, Bützow R, Virtanen I, Reventós J and Hukkanen M: Matrix metalloproteinase-2 and matrix metalloproteinase-9 codistribute with transcription factors RUNX1/AML1 and ETV5/ERM at the invasive front of endometrial and ovarian carcinoma. Hum Pathol 42: 57-67, 2011

73. Yan L, Lin B, Gao L, Gao S, Liu C, Wang C, Wang Y, Zhang S and Iwamori M: Lewis (y) antigen overexpression increases the expression of MMP-2 and MMP-9 and invasion of human ovarian cancer cells. Int J Mol Sci 11: 4441-4452, 2010.

74. Kamat AA, Fletcher M, Gruman LM, Mueller P, Lopez A, Landen CN Jr, Han L, Gershenson DM and Sood AK: The clinical relevance of stromal matrix metalloproteinase expression in ovarian cancer. Clin Cancer Res 12: 1707-1714, 2006.

75. Sawada K, Mitra AK, Radjabi AR, Bhaskar V, Kistner EO, Tretiakova M, Jagadeeswaran S, Montag A, Becker A, Kenny HA, et al: Loss of E-cadherin promotes ovarian cancer metastasis via alpha 5-integrin, which is a therapeutic target. Cancer Res 68: 2329-2339, 2008.

76. Paget S: The distribution of secondary growths in cancer of the breast. 1889. Cancer Metastasis Rev 8: 98-101, 1989.

77. Zhang Y, Ma B and Fan Q: Mechanisms of breast cancer bone metastasis. Cancer Lett 292: 1-7, 2010.

78. Mukherjee D and Zhao J: The role of chemokine receptor CXCR4 in breast cancer metastasis. Am J Cancer Res 3: 46-57, 2013.

79. Sonoda K: Novel therapeutic strategies to target RCAS1, which induces apoptosis via ectodomain shedding. Histol Histopathol 26: 1475-1486, 2011

80. Sonoda K, Miyamoto S, Hirakawa T, Yagi H, Yotsumoto F, Nakashima M, Watanabe $\mathrm{T}$ and Nakano $\mathrm{H}$ : Invasive potency related to RCAS1 expression in uterine cervical cancer. Gynecol Oncol 99: 189-198, 2005.

81. Skyldberg B, Salo S, Eriksson E, Aspenblad U, Moberger B, Tryggvason K and Auer G: Laminin-5 as a marker of invasiveness in cervical lesions. J Natl Cancer Inst 91: 1882-1887, 1999.

82. Brinkerhoff CE, Rutter JL and Benbow U: Interstitial collagenases as markers of tumor progression. Clin Cancer Res 6: 4823-4830, 2000.

83. Przybylo JA and Radisky DC: Matrix metalloproteinase-induced epithelial-mesenchymal transition: Tumor progression at Snail's pace. Int J Biochem Cell Biol 39: 1082-1088, 2007.

84. Sonoda K, Miyamoto S, Kobayashi H, Ogawa S, Okugawa K, Taniguchi $\mathrm{S}$ and Wake $\mathrm{N}$ : The level of RCAS1 expression is inversely correlated with the number of vimentin-positive stromal cells in epithelial ovarian cancer. Int J Gynecol Cancer 19: 838-843, 2009

85. Byun Y, Chen F, Chang R, Trivedi M, Green KJ and Cryns VL: Caspase cleavage of vimentin disrupts intermediate filaments and promotes apoptosis. Cell Death Differ 8: 443-450, 2001.

86. Eckes B, Dogic D, Colucci-Guyon E, Wang N, Maniotis A, Ingber D, Merckling A, Langa F, Aumailley M, Delouvée A, et al: Impaired mechanical stability, migration and contractile capacity in vimentin-deficient fibroblasts. J Cell Sci 111: 1897-1907, 1998

87. Nieminen M, Henttinen T, Merinen M, Marttila-Ichihara F, Eriksson JE and Jalkanen S: Vimentin function in lymphocyte adhesion and transcellular migration. Nat Cell Biol 8: 156-162, 2006.

88. Sonoda K, Miyamoto S, Yamazaki A, Kobayashi H, Nakashima M, Mekada E, and Wake N: Biologic significance of receptor-binding cancer antigen expressed on SiSo cells (RCAS1) as a pivotal regulator of tumor growth through angiogenesis in human uterine cancer. Cancer 110: 1979-1990, 2007.

89. Liby TA, Spyropoulos P, Buff Lindner H, Eldridge J, Beeson C, Hsu T and Muise-Helmericks RC: Akt3 controls vascular endothelial growth factor secretion and angiogenesis in ovarian cancer cells. Int J Cancer 130: 532-543, 2012

90. Davis GE and Senger DR: Endothelial extracellular matrix: Biosynthesis, remodeling, and functions during vascular morphogenesis and neovessel stabilization. Circ Res 97: 1093-1107, 2005.

91. American Cancer Society: Global Cancer Facts \& Figures: 3rd Edition. American Cancer Society, Atlanta, GA, pp34-36, 2015.

92. Schiffman M, Castle PE, Jeronimo J, et al: Human papillomavirus and cervical cancer. Lancet 370: 890-907, 2007. 
93. Burk RD, Chen Z and Van Doorslaer K: Human papillomaviruses: Genetic basis of carcinogenicity. Public Health Genomics 12: 281-290, 2009.

94. Moody CA and Laimins LA: Human papillomavirus oncoproteins: Pathways to transformation. Nat Rev Cancer 10: 550-560, 2010.

95. Buck CB, Day PM and Trus BL: The papillomavirus major capsid protein L1. Virology 445: 169-174, 2013.

96. Mammas IN, Sourvinos G, Giannoudis A and Spandidos DA: Human papilloma virus (HPV) and host cellular interactions. Pathol Oncol Res 14: 345-354, 2008.

97. Huang KF, Lee WY, Huang SC, Lin YS, Kang CY, Liou CP and Tzeng CC: Chromosomal gain of $3 \mathrm{q}$ and loss of 11q often associated with nodal metastasis in early stage cervical squamous cell carcinoma. J Formos Med Assoc 106: 894-902, 2007.

98. Giarnieri E, Zanesi N, Bottoni A, Alderisio M, Lukic A, Vecchione A, Ziparo V, Croce CM and Mancini R: Oncosuppressor proteins of fragile sites are reduced in cervical cancer. Cancer Lett 289: 40-45, 2010.

99. Samir R, Asplund A, Tot T, Pekar G and Hellberg D: High-risk HPV infection and CIN grade correlates to the expression of c-myc, CD4+, FHIT, E-cadherin, Ki-67, and p16INK4a. J Low Genit Tract Dis 15: 280-286, 2011.

100. Spandidos DA, Dokianakis DN, Kallergi G and Aggelakis E: Molecular basis of gynecological cancer. Ann N Y Acad Sci 900: 56-64, 2000.

101. Sonoda K, Kaku T, Kamura T, Nakashima M, Watanabe T and Nakano H: Tumor-associated antigen 22-1-1 expression in the uterine cervical squamous neoplasia. Clin Cancer Res 4 $1517-1520,1998$.

102. Wright JD, Barrena Medel NI, Sehouli J, Fujiwara K and Herzog TJ: Contemporary management of endometrial cancer Lancet 379: 1352-1360, 2012.

103. American Cancer Society: Cancer facts \& figures 2015. American Cancer Society, Atlanta, GA, pp24-25, 2015.

104. Sorosky JI: Endometrial cancer. Obstet Gynecol 120: 383-397, 2012.

105. Koornstra JJ, Mourits MJ, Sijmons RH, Leliveld AM, Hollema H and Kleibeuker JH: Management of extracolonic tumours in patients with Lynch syndrome. Lancet Oncol 10: 400-408, 2009

106. Matias-Guiu X and Prat J: Molecular pathology of endometrial carcinoma. Histopathology 62: 111-123, 2013.

107. Banno K, Yanokura M, Iida M, Masuda K and Aoki D: Carcinogenic mechanisms of endometrial cancer: Involvement of genetics and epigenetics. J Obstet Gynaecol Res 40: 1957-1967, 2014

108. Niwa K, Murase T, Furui T, Morishita S, Mori H, Tanaka T, Mori H and Tamaya T: Enhancing effects of estrogens on endometrial carcinogenesis initiated by N-methyl-N-nitrosourea in ICR mice. Jpn J Cancer Res 84: 951-955, 1993.

109. Ohgami T and Kato K: Pathogenesis of endometrial cancer. In Current Approaches to Endometrial Cancer. Sakuragi N and Silverberg SG (eds.) Future Medicine, London, pp18-32, 2014

110. Yeramian A, Moreno-Bueno G, Dolcet X, Catasus L, Abal M, Colas E, Reventos J, Palacios J, Prat J and Matias-Guiu X Endometrial carcinoma: Molecular alterations involved in tumor development and progression. Oncogene 32: 403-413, 2013.

111. MacDonald ND, Salvesen HB, Ryan A, Iversen OE, Akslen LA and Jacobs IJ: Frequency and prognostic impact of microsatellite instability in a large population-based study of endometrial carcinomas. Cancer Res 60: 1750-1752, 2000.

112. Hecht JL and Mutter GL. Molecular and pathologic aspects of endometrial carcinogenesis. J Clin Oncol 24: 4783-4791, 2006.

113. Halperin R, Zehavi S, Habler L, Hadas E, Bukovsky I and Schneider D: Comparative immunohistochemical study of endometrioid and serous papillary carcinoma of endometrium. Eur J Gynaecol Oncol 22: 122-126, 2001.

114. Holcomb K, Delatorre R, Pedemonte B, McLeod C, Anderson L and Chambers J: E-cadherin expression in endometrioid, papillary serous, and clear cell carcinoma of the endometrium. Obste Gynecol 100: 1290-1295, 2002.

115. Sonoda K, Kaku T, Hirakawa T, Kobayashi H, Amada S, Sakai K, Nakashima M, Watanabe T and Nakano $\mathrm{H}$ The clinical significance of tumor-associated antigen RCAS1 expression in the normal, hyperplastic, and malignant uterine endometrium. Gynecol Oncol 79: 424-429, 2000.

116. Sonoda K, Miyamoto S, Hirakawa T, Kaku T, Nakashima M, Watanabe T, Akazawa K, Fujita T and Nakano H: Association between RCAS1 expression and clinical outcome in uterine endometrial cancer. Br J Cancer 89: 546-551, 2003.
117.Landen CN Jr, Birrer MJ and Sood AK: Early events in the pathogenesis of epithelial ovarian cancer. J Clin Oncol 26 995-1005, 2008.

118.Gui T, Cao D, Yang J and Shen K: Tumor heterogeneity has important consequences for personalized medicine in ovarian cancer. Histol Histopathol 30: 173-181, 2015.

119. Mayr D, Hirschmann A, Löhrs U and Diebold J: KRAS and BRAF mutations in ovarian tumors: A comprehensive study of invasive carcinomas, borderline tumors and extraovarian implants. Gynecol Oncol 103: 883-887, 2006.

120.O'Neill CJ, Deavers MT, Malpica A, Foster $\mathrm{H}$ and McCluggage WG: An immunohistochemical comparison between low-grade and high-grade ovarian serous carcinomas: Significantly higher expression of p53, MIB1, BCL2, HER-2/neu, and C-KIT in high-grade neoplasms. Am J Surg Pathol 29: 1034-1041, 2005.

121. Nowee ME, Snijders AM, Rockx DA, de Wit RM, Kosma VM, Hämäläinen K, Schouten JP, Verheijen RH, van Diest PJ, Albertson DG and Dorsman JC: DNA profiling of primary serous ovarian and fallopian tube carcinomas with array comparative genomic hybridization and multiplex ligation-dependent probe amplification. J Pathol 213: 46-55, 2007.

122.Wiegand KC, Hennessy BT, Leung S, Wang Y, Ju Z, McGahren M, Kalloger SE, Finlayson S, Stemke-Hale K, $\mathrm{Lu} \mathrm{Y,} \mathrm{et} \mathrm{al:} \mathrm{A} \mathrm{functional} \mathrm{proteogenomic} \mathrm{analysis} \mathrm{of} \mathrm{endo-}$ metrioid and clear cell carcinomas using reverse phase protein array and mutation analysis: Protein expression is histotype-specific and loss of ARID1A/BAF250a is associated with AKT phosphorylation. BMC Cancer 14: 120, 2014

123. Naik JD, Seligmann J and Perren TJ: Mucinous tumours of the ovary. J Clin Pathol 65: 580-584, 2012.

124. George SH and Shaw P: BRCA and early events in the development of serous ovarian cancer. Front Oncol 4: 5, 2014.

125. Powell SN and Kachnic LA: Roles of BRCA1 and BRCA2 in homologous recombination, DNA replication fidelity and the cellular response to ionizing radiation. Oncogene 22: 5784-5791, 2003.

126. Venkitaraman AR: Linking the cellular functions of BRCA genes to cancer pathogenesis and treatment. Annu Rev Pathol 4: 461-487, 2009.

127. Risch HA, McLaughlin JR, Cole DE, Rosen B, Bradley L, Kwan E, Jack E, Vesprini DJ, Kuperstein G, Abrahamson JL, et al: Prevalence and penetrance of germline BRCA1 and BRCA2 mutations in a population series of 649 women with ovarian cancer. Am J Hum Genet 68: 700-710, 2001.

128. Antoniou A, Pharoah PD, Narod S, Risch HA, Eyfjord JE, Hopper JL, Loman N, Olsson H, Johannsson O, Borg $\mathrm{A}$, et al: Average risks of breast and ovarian cancer associated with BRCA1 or BRCA 2 mutations detected in case Series unselected for family history: A combined analysis of 22 studies. Am J Hum Genet 72: 1117-1130, 2003.

129. McLaughlin JR, Risch HA, Lubinski J, et al: Reproductive risk factors for ovarian cancer in carriers of BRCA1 or BRCA2 mutations: A case-control study. Lancet Oncol 8: 26-34, 2007.

130. Liu JF, Konstantinopoulos PA and Matulonis UA: PARP inhibitors in ovarian cancer: Current status and future promise. Gynecol Oncol 133: 362-369, 2014.

131.Ledermann J, Harter P, Gourley C, et al: Olaparib maintenance therapy in platinum-sensitive relapsed ovarian cancer. $\mathrm{N}$ Engl J Med 366: 1382-1392, 2012.

132. Fujita T, Miyamoto S, Onoyama I, et al: Expression of lysophosphatidic acid receptors and vascular endothelial growth factor mediating lysophosphatidic acid in the development of human ovarian cancer. Cancer Lett 192: 161-169, 2003.

133. Yotsumoto F, Yagi H, Suzuki SO, et al: Validation of HB-EGF and amphiregulin as targets for human cancer therapy. Biochem Biophys Res Commun 365: 555-561, 2008.

134. Yagi H, Yotsumoto F, Sonoda K, et al: Synergistic anti-tumor effect of paclitaxel with CRM197, an inhibitor of HB-EGF, in ovarian cancer. Int J Cancer 124: 1429-1439, 2009. 